\title{
HUBUNGAN BEBAN KERJA DENGAN KEPUASAN KERJA PERAWAT DI RUANGAN PERAWATAN DEWASA RSU GMIM PANCARAN KASIH MANADO
}

\author{
Kifly Franco Barahama \\ Mario Katuuk \\ Wenda M. Oroh \\ Program Studi Ilmu Keperawatan Fakultas Kedokteran \\ Universitas Sam Ratulangi \\ Email : Kiflybarahama6@gmail.com
}

\begin{abstract}
Workload is a comparison between actual workload and effective work time. Job satisfaction is the level of one's feelings after comparing the performance / results they feel with their expectations. Based on a preliminary study at the RSU GMIM Pancaran Kasih Manado Hospital that the number of nurses is not proportional to the number of patients, so each nurse is responsible for 10-11 patients, so complaints from several nurses about shifting or overtime are often hear. Purpose of the research was to determine the relationship workload and job satisfaction of nurses in the adult care room of RSU GMIM Pancaran Kasih Manado. This research method uses analytical design with Cross Sectional approach. Sample with a total sampling technique of 58 respondents. The data obtained was processed using Chi-square test with a degree of significance $(\alpha)=0.05$. Conclusion there is a workload relationship with job satisfaction with a value of $p(0,000)$.

Keywords : Workload, Job Satisfaction
\end{abstract}

\begin{abstract}
Abstrak : Beban kerja merupakan perbandingan antara beban kerja aktual dan waktu kerja efektif. Kepuasan kerja merupakan tingkat perasaan seseorang setelah membandingkan kinerja/hasil yang dirasakannya dengan harapannya. Berdasarkan studi pendahuluan di RSU GMIM Pancaran Kasih Manado bahwa jumlah perawat tidak sebanding dengan jumlah pasien, sehingga setiap perawat bertanggung jawab terhadap 10-11 pasien, sehingga sering terdengar keluhan dari beberapa perawat tentang jadwal shift atau lembur yang tidak menentu. Tujuan penelitian adalah untuk mengetahui hubungan beban kerja dengan kepuasan kerja perawat di ruangan perawatan dewasa RSU GMIM Pancaran Kasih Manado. Metode penelitian ini menggunakan desain analitik dengan pendekatan Cross Sectional. Sampel dengan teknik pengambilan total sampel sebanyak 58 responden. Data yang diperoleh diolah menggunakan uji Chi-square dengan derajat kemaknaan $(\alpha)=0,05$. Kesimpulan, ada hubungan beban kerja dengan kepuasan kerja dengan nilai $p(0,000)$.
\end{abstract}

Kata kunci : Beban kerja, Kepuasan kerja. 


\section{PENDAHULUAN}

Pelayanan keperawatan merupakan pelayanan/ asuhan profesional yang diberikan kepada pasien bersifat humanistis, menggunakan pendekatan holistik, dilakukan berdasarkan kiat keperawatan, berorientasi pada kebutuhan objektif pasien, mengacu pada standar profesional keperawatan dan menggunakan etika keperawatan sebagai tuntutan utama (Nursalam, 2014). Pelayanan keperawatan yang bermutu dapat dicapai apabila ada keseimbangan antara jumlah tenaga dengan beban kerja perawat di suatu rumah sakit (Pusat Data dan Informasi Kemenkes RI, 2017). Tingginya aktivitas tenaga perawat dalam melayani pasien akan mempengaruhi hasil kerjanya (Nurjanah, 2016).

Keberhasilan dalam memberikan pelayanan secara profesional melibatkan berbagai tenaga kesehatan, salah satu diantaranya yang terlibat secara langsung dalam pemberian pelayanan kepada pasien ialah perawat. Jumlah perawat merupakan yang paling dominan diantara tenaga kesehatan yang lain. Hal tersebut juga didukung oleh pernyataan bahwa proporsi tenaga kesehatan terbanyak adalah perawat dengan jumlah 33,3\% (Profil Kesehatan Indonesia, 2016). Selain itu juga pelayanan keperawatan yang diberikan kepada pasien selama 24 jam. Sehingga sangat perlu diperhatikan beban kerja perawat dalam memberikan pelayanan kesehatan (Nurjanah, 2016).

Beban kerja perawat merupakan seluruh kegiatan atau aktivitas yang dilakukan oleh perawat selama tugas disuatu unit pelayanan keperawatan. Beban kerja meliputi beban kerja fisik maupun mental. Beban kerja yang terlalu berat atau kemampuan fisik yang terlalu lemah dapat mengakibatkan seorang pekerja menderita gangguan atau penyakit akibat kerja (Efendy, 2009). Beban kerja perawat dapat dilihat dari aspek seperti tugas yang dijalankan berdasarkan fungsi utama dan fungsi tambahan yang dikerjakan, jumlah pasien yang dirawat per hari, per bulan dan per tahun, kondisi pasien, rata-rata pasien dirawat, tindakan langsung dan tidak langsung yang dibutuhkan pasien, frekuensi masing-masing tindakan yang diperlukan dan rata-rata waktu yang dibutuhkan dalam melaksanakan tindakan (Nursalam, 2014). Analisa beban kerja perawat dapat dilihat dari aspek-aspek seperti tugas-tugas yang dijalankan berdasarkan fungsi utama dan tugas tambahan yang dikerjakan, jumlah pasien yang harus dirawat, kapasitas kerjanya sesuai dengan pendidikan yang diperoleh, waktu kerja yang digunakan untuk mengerjakan tugasnya sesuai dengan jam kerja yang berlangsung setiap hari, serta kelengkapan fasilitas yang dapat membantu perawat menyelesaikan kerjanya dengan baik (Syaer, 2010).

Hasil penelitian dari Rubbiana (2015) menunjukkan beban kerja terbanyak yang dilakukan oleh perawat yaitu keperawatan tidak langsung. Tingginya pelaksanaan kegiatan perawat tidak langsung dikarenakan kegiatan ini merupakan kegiatan pelaporan rutin perawat kepada kepala ruangan terkait jumlah pasien, kondisi pasien dan tindakan keperawatan. Faktor-faktor yang mempengaruhi beban kerja perawat adalah tuntutan situasi dan pengaruh eksternal dimana seorang perawat akan melaksanakan tugas-tugas keperawatan dibangsal sehingga dirasa memberatkan perawat. Beban kerja yang terlalu berlebihan akan menimbulkan kelelahan baik fisik atau mental dan reaksireaksi emosional. Sedangkan pada beban kerja yang terlalu sedikit di mana pekerjaan yang terjadi karena pengulangan gerak akan menimbulkan kebosanan dalam kerja rutin sehari-hari (Mastini, 2013).

Beban kerja dapat mempengaruhi kepuasan kerja perawat. Beban kerja yang tidak proporsional akan berdampak pada rasa stres, terutama yang telah melampaui tingkat moderat akan menimbulkan dampak negatif, yaitu ketidakpuasan kerja yang selanjutnya akan berdampak pada motivasi yang rendah (Hamid, 2014). Kepuasan kerja staf dapat dilihat dari terpenuhinya kebutuhan fisik dan psikis, dimana kebutuhan psikis dapat terpenuhi melalui peran manajer dalam memperlakukan stafnya (Nursalam, 2007). 
Kepuasan kerja menyangkut sikap umum seorang individu terhadap pekerjaannya, seorang dengan tingkat kepuasan kerja tinggi menunjukkan sikap yang positif terhadap pekerjaannya itu, sebaliknya jika karyawan tidak memperoleh kepuasan kerja tidak semata akan mencapai kematangan psikologis dan dampaknya akan menjadi frustasi, cepat lelah, bosan, emosinya tidak stabil, sering absen dan melakukan kesibukan yang tidak ada hubungannya dengan pekerjaan (Hasibuan, 2016).

Kepuasan kerja merupakan hasil dari berbagai macam sikap (attitude) yang dimiliki oleh perawat. Sikap ini adalah halhal yang berhubungan dengan pekerjaan beserta faktor-faktor yang spesifik seperti pengawasan atau supervisi, gaji dan tunjangan, kesempatan untuk mendapatkan promosi dan kenaikan pangkat, kondisi kerja, pengalaman terhadap kecakapan, penilaian kerja dan yang adil dan tidak merugikan hubungan sosial didalampekerjaan yang baik, penyelesaian yang cepat terhadap keluhan-keluhan dan perlakuan yang baik dari pimpinan terhadap karyawan. Ketidakpuasan kerja karyawan akan berdampak pada menurunnya motivasi kerja, menurunnya loyalitas kerja (Tahsinia, 2013).

Hasil penelitian kepuasan kerja yang dilakukan oleh Sugiri (2015) di ruangan Nakula RSUD Sanjiwani Gianyar didapatkan bahwa kepuasan kerja yang baik secara tidak langsung akan berpengaruh terhadap kinerja pegawai itu sendiri. Semakin tinggi kepuasan kerja perawat semakin tinggi kinerjanya. Hasil penelitian lain yang dilakukan oleh Sutarni (2008) menunjukkan bahwa ada hubungan yang bermakna antara beban kerja dengan kepuasan kerja dengan nilai $\mathrm{OR}=17,333$, artinya beban kerja berat mempunyai peluang 17,333 kali untuk kepuasan kerja dibanding dengan beban kerja ringan.

Berdasarkan hasil studi pendahuluan melalui observasi dan wawancara dengan kepala perawat dan beberapa perawat di RSU GMIM Pancaran Kasih Manado pada bulan Februari 2018, didapatkan data bahwa jumlah perawat di lima ruangan perawatan dewasa (Hana, Lukas, Yehezkiel, Sara dan Ribka) sebanyak 58 orang perawat, jumlah pasien pada tiga bulan terakhir yaitu bulan November 2017 s.d Januari 2018 sebanyak 1065 orang dengan kapasitas 121 tempat tidur. Sistem pemberian asuhan keperawatan menggunakan metode tim dimana setiap tim memiliki 1 orang ketua tim perawat primer dan 6 orang anggota tim, setiap perawat bertanggung jawab terhadap 3-4 pasien. Seringkali terdengar keluhan dari beberapa perawat tentang jadwal shift atau lembur yang tidak menentu dan beban kerja yang cukup tinggi dirasakan oleh perawat terjadi pada shift sore (3-4 perawat) dan malam hari (2-3 perawat) sehingga jumlah perawat tidak sebanding dengan jumlah pasien, sehingga setiap perawat bertanggung jawab terhadap 10-11 pasien, dengan demikian beban kerja perawat pun meningkat. Berdasarkan uraian di atas penulis ingin meneliti hubungan antara beban kerja dengan kepuasan kerja perawat di Ruangan Perawatan Dewasa RSU GMIM Pancaran Kasih Manado.

\section{METODE PENELETIAN}

Penelitian yang digunakan bersifat analitik dengan pendekatan Cross Sectional yaitu variabel sebab atau resiko dan akibat atau kasus yang terjadi pada objek penelitian diukur atau dikumpulkan secara simultan, satu kali saja dalam waktu yang bersamaan (Setiadi, 2013). Penelitian ini telah dilaksanakan di Ruangan Perawatan Dewasa RSU GMIM Pancaran Kasih Manado yaitu ruangan Hana, Lukas, Yehezkiel, Sara dan Ribka pada bulan Juni sampai Desember 2018. Populasi dalam penelitian ini yaitu seluruh perawat pelaksana yang ada di Ruangan Hana, Lukas, Yehezkiel, Sara dan Ribka RSU GMIM Pancaran Kasih Manado berjumlah 58 orang. Teknik pengambilan sampel yang digunakan yaitu total sampel sebanyak 58 orang.

Instrument pengumpulan data yang digunakan yaitu kuesioner. Kuesioner beban kerja yang pernah digunakan oleh Pitaloka (2010) yang terdiri dari 15 pernyataan dengan alternative jawaban 
sangat tidak setuju skor 1, tidak setuju skor 2, kurang setuju skor 3, setuju skor 4, sangat setuju skor 5. Sedangkan untuk kuesioner kepuasan kerja pernah digunakan oleh Panjaitan (2014) terdiri dari 20 pernyataan dengan alternative jawaban sangat tidak puas skor 1, tidak puas skor 2, kurang puas skor 3 , puas skor 4 , Sangat puas skor 5.

Prosedur pengolahan data yang dilakukan melalui tahap editing, coding,entry data dan tabulating. Analisa data yang dilakukan meliputi analisa univariat yang menghasilkan distribusi frekuensi berdasarkan presentase dari tiaptiap karakteristik variabel dan analisa bivariat digunakan untuk mengetahui hubungan antara dua variabel dengan menggunakan uji Chi-square dengan tingkat kemaknaan 95\% $\quad(\alpha \leq 0,05)$ (Sujawerni, 2014).

\section{HASIL dan PEMBAHASAN}

\section{A. Karakteristik Responden}

Tabel 1. Distribusi Responden Berdasarkan Usia $(\mathrm{N}=58)$.

\begin{tabular}{ccc}
\hline Usia & f & \% \\
\hline$<28$ Tahun & 37 & 63,8 \\
$\geq 28$ Tahun & 21 & 36,2 \\
\hline Jumlah & $\mathbf{5 8}$ & $\mathbf{1 0 0}$ \\
\hline
\end{tabular}

Sumber : Data Primer 2018

Berdasarkan data pada tabel diatas menunjukkan bahwa lebih banyak responden berusia < 28 Tahun yaitu 37 responden $(63,8 \%)$ sedangkan sisanya berusia 28 tahun yaitu 21 responden $(36 \%)$. Robbin (2006) menyatakan bahwa umur bukan merupakan faktor penentu dalam menampilkan kinerja yang positif ditempat kerja, tetapi komitmen dari individu untuk melakukan yang terbaik di tempat kerja. Menurut peneliti usia bukan salah satu faktor penentu bahwa seorang akan puas di dalam pekerjaannya, walaupun usia masih muda tetapi mempunyai komitmen untuk maju dan berkembang maka mereka akan berupaya bekerja dengan baik dan mencapai kepuasan kerja.
Tabel 2. Distribusi Responden Berdasarkan Tingkat Pendidikan ( $\mathrm{N}=58)$.

\begin{tabular}{ccc}
\hline Tingkat Pendidikan & f & \% \\
\hline D-III & 36 & 62,1 \\
S-1/ Profesi Ners & 22 & 37,9 \\
\hline Jumlah & 58 & 100 \\
\hline
\end{tabular}

Sumber : Data Primer 2018

Berdasarkan data pada tabel diatas menunjukkan bahwa tingkat pendidikan responden yang lebih banyak D-III yaitu sebanyak 36 responden $(62,1 \%)$ dan sisanya S1/Profesi Ners yaitu sebanyak 22 responden (37,9\%). Menurut pendapat Gillies (1994) bahwa perawat yang mempunyai pendidikan lebih tinggi juga memiliki kemampuan kerja yang lebih tinggi sehingga memiliki tuntutan yang tinggi terhadap organisasi dan berdampak kepada kepuasan. Menurut peneliti ratarata perawat pelaksana tingkat pendidikannya D-III Keperawatan dimana mereka berupaya menunjukkan kinerjanya yang baik untuk peningkatan karir, kemungkinan yang belum mendapatkan kesempatan dapat terjadi penurunan dalam bekerja.

Tabel 3. Distribusi Responden Berdasarkan Lama Kerja di RS ( $\mathrm{N}=58)$.

\begin{tabular}{ccc}
\hline Lama Kerja di RS & $\mathbf{f}$ & $\mathbf{\%}$ \\
\hline$<5$ Tahun & 36 & 62,1 \\
$\geq 5$ Tahun & 22 & 37,9 \\
\hline Jumlah & $\mathbf{5 8}$ & $\mathbf{1 0 0}$ \\
\hline
\end{tabular}

Sumber : Data Primer 2018

Berdasarkan data pada tabel diatas menunjukkan bahwa lama kerja yang tertinggi yaitu < 5 Tahun yaitu 36 responden $(62,1 \%)$ sedangkan sisanya $\geq 5$ Tahun 22 responden (37,9\%). Lama kerja dapat mempengaruhi kinerja dan kepuasan kerja. Perawat pelaksana dalam melakukan tindakan keperawatan akan semakin terampil bila sering digunakan dan bertambahnya pengalaman. Hal ini sesuai dengan pendapat Siagian (2007) bahwa semakin lama seseorang bekerja akan semakin terampil dan berpengalaman menghadapi masalah dalam pekerjaannya. 
Tabel 4. Distribusi Responden Berdasakan Status Perkawinan $(\mathrm{N}=58)$.

\begin{tabular}{ccc}
\hline Status Perkawinan & f & \% \\
\hline Belum Kawin & 33 & 56,9 \\
Kawin & 25 & 43,1 \\
\hline Jumlah & $\mathbf{5 8}$ & $\mathbf{1 0 0}$ \\
\hline Sumber : Data Primer 2018 & &
\end{tabular}

Berdasarkan data pada tabel diatas menunjukkan bahwa status perkawinan responden yang tertinggi yaitu belum kawin 33 responden $(56,9 \%)$ dan sisanya yaitu kawin 25 responden $(43,1 \%)$. Hasil penelitian dari Rachman (2006) bahwa tidak ada hubungan yang bermakna antara kepuasan kerja perawat yang kawin dan belum kawin,. Sementara hasil riset Robbin (2006), bahwa karyawan yang kawin lebih rendah tingkat keabsenannya, mempunyai tingkat pengunduran diri yang lebih rendah dan lebih puas dengan pekerjaannya dibandingkan dengan yang belum kawin.

\section{B. Analisis Univariat}

Tabel 5. Distribusi Responden Berdasarkan Beban Kerja $(\mathrm{N}=58)$.

\begin{tabular}{ccc}
\hline Beban Kerja & f & \% \\
\hline Ringan & 19 & 32,8 \\
Berat & 39 & 67,7 \\
\hline Jumlah & $\mathbf{5 8}$ & $\mathbf{1 0 0}$ \\
\hline Sumber $:$ Data Primer 2018 & &
\end{tabular}

Sumber : Data Primer 2018

Berdasarkan data pada tabel diatas menunjukkan bahwa beban kerja perawat di Ruangan Perawatan Dewasa RSU GMIM Pancaran Kasih Manado adalah berat sebanyak 39 responden $(67,2 \%)$ sedangkan beban kerja ringan sebanyak 19 responden $(32,8 \%)$. Beban kerja perawat adalah menghitung aktivitas kerja perawat dan ketergantungan klien pada pelayanan keperawatan. Aktifitas perawat dibedakan menjadi perawatan langsung dan tidak langsung (Nursalam, 2014).

Hasil penelitian ini sesuai dengan penelitian yang dilakukan Sutarni (2008) bahwa beban kerja perawat adalah berat sebesar $62,3 \%$. Hal lain yang dapat memperberat beban kerja perawat di Ruangan Perawatan Dewasa RSU GMIM Pancaran Kasih Manado adalah belum maksimalnya pengaturan tenaga berdasarkan tingkat ketergantungan pasien yang dirawat dan ditambah dengan tugas perawatan yang tak langsung atau pekerjaan yang tidak berhubungan dengan pemenuhan kebutuhan pasien baik fisik, psikologis, sosial dan spiritual yaitu seperti membuat rencana perawat, menyiapkan alat, konsultasi dengan angggota tim, menulis dan membaca catatan kesehatan dan melaporkan kondisi pasien sehingga akan banyak tindakan yang dilakukan. Ilyas (2004) mengatakan beban kerja perawat yang tinggi dapat menyebabkan keletihan, kelelahan. Sehingga perlu dikelola dengan baik oleh manger keperawatan untuk menjaga mutu pelayanan yang baik dan tenaga yang berkualitas.

Tabel 6. Distribusi Responden Berdasarkan Kepuasan Kerja Perawat ( $\mathrm{N}=$ 58).

\begin{tabular}{ccc}
\hline Kepuasan Kerja & f & $\mathbf{\%}$ \\
\hline Kurang Puas & 30 & 51.7 \\
Puas & 28 & 48,3 \\
\hline Jumlah & $\mathbf{5 8}$ & $\mathbf{1 0 0}$ \\
\hline Sumber : Data Primer 2018 & &
\end{tabular}

Berdasarkan data pada tabel diatas menunjukkan bahwa kepuasan kerja perawat di Ruangan Perawatan Dewasa RSU GMIM Pancaran Kasih Manado adalah kurang puas sebanyak 30 responden (51.7\%) sedangkan yang puas sebanyak 28 responden (48,3\%). Kepuasan kerja merupakan tingkat perasaan seseorang setelah membandingkan kinerja/ hasil yang dirasakannya dengan harapannya (Hamid, 2014). Hasil penelitian ini sesuai dengan penelitian yang dilakukan oleh Sutarni (2008) yang menunjukkan bahwa kepuasan kerja perawat kurang puas sebesar $54.5 \%$. Hal yang dapat membuat mempengaruhi kepuasan kerja perawat adalah lama kerja. Perawat dalam melaksanakan kegiatan keperawatan banyak melakukan tindakan (keterampilan), tindakan keperawatan akan semakin terampil apabila sering digunakan dan bertambahnya pengalaman. Hal ini sesuai dengan pendapat Siagian (2007) 
bahwa semakin lama seorang bekerja akan semakin terampil dan berpengalaman dalam menghadapi masalah. Kondisi tersebut dimungkinkan karena rata-rata lama kerja perawat di RSU GMIM Pancaran Kasih Manado adalah 5-7 tahun Dari segi keterampilan perawat yang lama kerjanya lebih lama akan semakin terampil dalam pekerjaannya karena makin sering melakukan tindakan keperawatan dilakukan dan bertambahnya pengalaman.

\section{Analisis Bivariat}

Tabel 7. Analisis hubungan beban kerja dengan kepuasan kerja perawat di Ruangan Perawatan Dewasa RSU Pancaran Kasih GMIM Manado

\begin{tabular}{lccccccc}
\hline \multirow{2}{*}{$\begin{array}{c}\text { Skor } \\
\text { Keban } \\
\text { Kerja }\end{array}$} & \multicolumn{6}{c}{ Skor Kepuasan } & P \\
\cline { 2 - 6 } & Kurang Puas & \multicolumn{2}{c}{ Puas } & \multicolumn{2}{c}{ Total } & Value \\
\cline { 2 - 6 } Ringan & 1 & 5,3 & 18 & 94,7 & 19 & 100 & 0,000 \\
Berat & 29 & 74,4 & 10 & 25,6 & 39 & 100 & \\
\hline Total & 30 & 51,7 & 28 & 48,3 & 58 & 100 & \\
\hline Sumber : & Data & Primer & 2018 & &
\end{tabular}

Berdasarkan hasil penelitian pada tabel diatas menunjukkan hubungan yang bermakna antara beban kerja dengan kepuasan kerja $(\rho=0,000)$ yang berarti ada hubungan yang signifikan antara beban kerja dan kepuasan kerja. Berdasarkan hasil analisis data yang dilakukan untuk menguji hubungan antara beban kerja dengan kepuasan kerja perawat diperlihatkan bahwa antara kedua variabel tersebut menunjukkan ada hubungan yang signifikan. Selanjutnya dapat dinyatakan bahwa makin tinggi beban kerja maka semakin rendah tingkat kepuasan kerja perawat.

Berdasarkan data hasil penelitian yang diperoleh, sesuai dengan konsep yang menerangkan hubungan positif antara beban kerja dengan kepuasan kerja. Altaf dan Mohamad Atif, (2011) menyatakan bahwa beban kerja berpengaruh negatif terhadap kepuasan kerja. Beban kerja yang tinggi memiliki pengaruh yang negatif terhadap kepuasan kerja. Pada penelitian Mustapha, (2013) menyatakan bahwa kepuasan kerja dipengaruhi oleh beban kerja sehari-hari, karyawan lebih puas ketika mereka diberikan beban kerja yang lebih rendah. Kepuasan kerja yang lebih rendah ditemukan pada beban kerja yang lebih tinggi dalam penelitian Mansoor, dkk, (2011). Dalam Tunggareni dan Thinni, (2013) mengemukakan bahwa tenaga keperawatan yang memiliki beban kerja objektif sedang cenderung memiliki tingkat kepuasan kerja yang lebih besar dari beban kerja objektif tinggi.

Keperawatan merupakan pekerjaan yang memerlukan keanekaragaman keterampilan, mempunyai identitas tugas, merupakan tugas yang berarti, perlu otonomi dan umpan balik pekerjaan. Kinerja dan kepuasan merupakan tingkat dimana karyawan mencapai persyaratanpersyaratan pekerjaan. Sehingga pengaturan atau penilaan dari manajer keperawatan pun harus dilakukan dengan dengan baik (Nursalam, 2014). Menurut peneliti beban kerja terasa berat bila tidak diimbangi dengan jumlah tenaga yang sesuai, uraian tugas yang tidak jelas, dan tidak diimbangi dengan penambahan ilmu dan keterampilan yang berkesinambungan. Selain itu lama kerja juga akan berpengaruh kepada pekerjaan sehingga dikatakan perawat yang mempunyai pengalaman yang lama maka perawat tersebut menjadi makin terampil. Hal ini sesuai pendapat Siagian (2007) bahwa semakin lama seorang bekerja akan semakin terampil dan berpengalaman dalam menghadapi masalah dalam pekerjaannya. Berdasarkan hasil penelitian, kondisi saat ini perawat di Ruangan Perawatan Dewasa RSU GMIM Pancaran Kasih Manado sudah puas dengan beban kerja yang dikategorikan berat, maka diharapkan pengelola rumah sakit harus mempertahankan atau meningkatkan tingkat kepuasan kerja perawat.

\section{SIMPULAN}

Hasil penelitian yang dilakukan terhadap 58 responden dapat disimpulkan bahwa beban kerja perawat di Ruangan Perawatan Dewasa RSU GMIM Pancaran Kasih Manado berada pada beban kerja berat, kepuasan kerja perawat di Ruangan Perawatan Dewasa RSU GMIM Pancaran 
Kasih Manado berada pada kurang puas dan terdapat hubungan yang signifikan antara beban kerja dan kepuasan kerja perawat di Ruangan Perawatan Dewasa RSU GMIM Pancaran Kasih Manado.

\section{DAFTAR PUSTAKA}

Altaf dan Atif, M. (2011). Moderating Affect of Workplace Spirituality on the Relation of thr Job Overload and Job Satisfaction. Journal of Business Ethics

Efendy F. (2009). Keperawatan Kesehatan Komunitas Teori dan Praktik Dalam Keperawatan.Jakarta: Salemba Medika

Gillies, D.A. (1994). Nursing management a system approach. ( $\left.3^{\text {th }} \mathrm{ed}\right)$. Philadelphia: W.B. Sounders Company

Hamid, S. (2014).Manajemen Sumber Daya Manusia Lanjutan.Yogyakarta: Deepublish

Hasibuan, M.S.P. (2016). Manajemen Dasar, Pengertian dan Masalah. Jakarta: Buni Aksara

Ilyas, Y. (2004). Perencanaan SDM rumah sakit teori, metode dan formula. (Edisi revisi). Jawa Barat: FKM-UI

Mansoor, dkk (2011). The Impact of Job Stres on Employee Job Satisfaction A study on Telecommunication Sector of Pakistan. Journal of Business Studies Quarterly

Mastini, I, GST, A, A, P. (2013), Hubungan Pengetahuan, Sikap, dan Beban Kerja dengan Kelengkapan Pendokumentasian Asuhan Keperawatan Irna di Rumah Sakit Umum Pusat Sanglah Denpasar. Tesis. Universitas Udayana Denpasar

Mustapha, Noraani dan Ghee, W, Y. (2013). ExaminingFaculty Workload as Antencedent of Job Satisfaction among Academic Staff of Higher Public Education on Kelantan Malaysia. Journal Business and Management Horizons

Nurjanah S. (2016). Analisis Beban Kerja Tenaga Perawat di Instalasi Rawat Inap Rumah Sakit Umum Daerah (RSUD) Kota Kendari 2016

Nursalam, (2007). Manajemen Keperawatan: Aplikasi Dalam Praktek Keperawatan Profesional. (edisi 2). Jakarta: Salemba Medika.

Nursalam, (2014). Manajemen Keperawatan: Aplikasi Dalam Praktek Keperawatan Profesional. (Edisi 4). Jakarta: Salemba Medika.

Panjaitan E.S. (2014). Tingkat Kepuasan Kerja Perawat Pelaksana di Ruang Rawat Inap RS. TK. II Putri Hijau Medan.

Pitaloka D. (2010). Pengaruh Kondisi Kerja Dan Beban Kerja Terhadap Stres Kerja Pada Perawat di Ruang Rawat Inap RSU Kaban Jahe Kab. KaroTahun 2010.

Profil Kesehatan Indonesia Tahun 2016. Jakarta: Kementerian Kesehatan RI. 2017

Pusat Data dan Informasi 2017. Jakarta Selatan: Kementerian Kesehatan RI

Rachman, D. (2006). Hubungan Persepsi Perawat Pelaksana Tentang Supervisi Karu dan Penghargaan dengan Kepusan Kerja. Di Ruang Rawat Inap. Tesis: Program Pasca Sarjana FIK UI, tidak dipublikasikan.

Robbin, P. S. (2006), Perilaku Organisasi Konsep Kontraversi dan Aplikas. Edisi bahasa Indonesia. Jakarta; PT. Prenhallindo

Rubbiana, N, I. (2015). Analisis Beban Kerja dan Kebutuhan Tenaga Perawat 
e-journal Keperawatan (e-Kp) Volume 7 Nomor 1, Februari 2019

Pelaksana dengan Metode Workload Indicator staff need (WISN) di Instalasi Rawat Inap Tulip RSUD Kota Bekasi

Setiadi, (2013). Konsep dan Praktek Penulisan Risat Keperawatan Edisi 2.Yogyakarta : Graha Ilmu.

Siagian, (2007). Manajemen sumber daya manusia. Jakarta: PT. Bumi Aksara

Sugiri I.M (2015). Hubungan Beban Kerja, Stres Kerja Dengan Kepuasan Kerja Perawat Di Ruangan Nakula RSUD Sanjiwani Gianyar.

Sujawerni V. Wiratma (2014). Metodologi penelitian kesehatan. Yogyakarta: Graha Media.

Sutarni, Nani (2008). Hubungan Beban Kerja dengan Kepuasan Kerja Perawat Pelaksana di Instalasi Rawat Inap Rumah Sakit Kanker Dharmais Jakarta.

Syaer, Syafrudin. (2010). Beban Kerja Perawat Unit Gawat Darurat di Rumah Sakit Umum Lasinrang Kabupaten Pinrang Tahun 2010.

Tahsinia. (2013). Faktor-faktor Yang Berhubungan Dengan Kepuasan Kerja Perawat Di RS. Rumah Sehat Terpadu Parung, Bogor Tahun 2013

Tunggareni dan Thinni, (2013). Job Satisfaction and Performance of Nurce based on Workload in Bhayangkara Hospital Lumajang. Jurnal Administrasi Kesehatan Indonesia 